\title{
Correction to: Optical and photovoltaic properties of vacuum evaporated CZTSe, CAZTSe and AZTSe thin films: a comparative study
}

J. Henry ${ }^{1}$, G. Sivakumar ${ }^{2}$, R. Vettumperumal ${ }^{3}$, T. Senthil Siva Subramanian ${ }^{4}$, and K. Mohanraj ${ }^{1, *}$ (i)

${ }^{1}$ Department of Physics, Manonmaniam Sundaranar University, Tirunelveli, Tamil Nadu 627012 , India

${ }^{2}$ Centralised Instrumentation and Service Laboratory (CISL), Department of Physics, Annamalai University, Annamalai Nagar, Tamil Nadu 608 002, India

${ }^{3}$ Department of Physics, Fodhdhoo School, Fodhdhoo 04120, Noonu Atoll, Republic of Maldives

${ }^{4}$ Hindustan College of Science and Technology, Mathura, Uttar Pradesh, India

Published online:

22 July 2021

(C) Springer Science+Business Media, LLC, part of Springer Nature 2021

\section{Correction to:}

Journal of Materials Science:

Materials in Electronics

https://doi.org/10.1007/s10854-021-06529-7
Publisher's Note Springer Nature remains neutral with regard to jurisdictional claims in published maps and institutional affiliations.

In the original version of this article, the supplementary file was published with wrong title. The supplementary file with the updated title has been replaced in the original article.

The original article can be found online at https:// doi.org/10.1007/s10854-021-06529-7.

Address correspondence to E-mail: mohanraj@msuniv.ac.in; kmohanraj.msu@gmail.com 